\title{
And a Little Child Shall Lead Them
}

Mary Dombeck

University of Rochester

The title phrase occurs in a Biblical image of an idealized and longedfor era where the justice in the social order is symbolically reflected in the animal kingdom. The poetry is meant to extend images beyond common sense. The right order to be established portrays a time when the natural enmity between different species ceases and a place safe enough for a child to lead them. ${ }^{1}$

The vivid imagery of such a passage is reminiscent of dream imagery where truth is existential rather than factual. The poetry conveys the contrast of what is hoped for in a world where in reality the social order is not just and where there is danger for humans, especially for the most vulnerable of them, the child.

This article is about a dream of great danger. It was dreamed by a nine-year-old girl who gives little more than the text of her dream. The interpreter is challenged to enter the experience of the dream and her own experience. As she considers it in relation to another story, a myth, she draws closer to an understanding of the danger portrayed in the world of the child.

This phenomenological hermeneutic analysis establishes a dialogue between the dream, the myth, the interpreter, and the dreamer. It sets up a process that fuses the boundaries of each without blurring them. Thus the understanding of the dream, the myth, and the interpreter herself are expanded, and the world of the child is manifested in more depth.

Human beings are dreamers and myth makers who must not only express their visions but also explicate their expressions. However, it is a peculiarity of western people that the last place they would look for explanations is in their dreams or in their children. It is also a peculiarity of western people that they like to explicate things cognitively. In working with a dream or a myth we tend to want to ask the question "what does it mean?"

The question suggests that the dream or the myth and the symbols with which it is said stand for or suggests something else, namely, the "real" meaning. We are, unfortunately, tempted to think of the dream as a substitute for reality and of the dream symbols as fixed proxies or

Phenomenology + Pedagogy Volume 101992 
outward coverings of the "real thing." When a symbol is considered in this way it can be said to be frozen. Conversely, a fluid symbol is dynamic and active. It acts like a telescope by making available to our understanding a world too big for our naked eye, and at the same time it acts like a microscope, increasing the visibility of what was previously too small to see. A symbol when it is fluid allows for telescoping and microscoping and for the expression of emotion.

In this article dream and myth are not objects of work, but rather are participants with the dreamer, and reader or hearer in a process of understanding. The question is not "What does it mean?" but "How does it mean?" and "Who is addressed?"

\section{The Dream}

This project started with a curiosity about the appearance of the four basic elements fire, water, air, and earth as symbols in the dreams of children. The children in a small private elementary school were asked to write or draw the most vivid dream they have ever had. The request was regarded with enthusiasm. The younger children did drawings, the older ones wrote them, and some did both. There was a fair distribution of monsters, superpeople, fairylands, outer space, and water. Many of the symbols did not lend themselves to being neatly sorted into the four basic elements. There were many nightmares as well as happy dreams, and there were many anxious dreams with happy endings. I emerged with 50 well-articulated dreams where water symbolism could be clearly identified.

In these dreams water was experienced by the dreamers in a variety of ways. Water was variously described as annoying, pleasurable, neutral, manageable, unmanageable, dangerous, life-giving, deadly, and taken for granted.

While reading these dreams I came across one that seemed especially attractive to me:

I had a dream that our house had all water in it. I forgot about my mother and just ran out of the house. Then I said, "If she is dead, I am going to kill myself." When I looked through the door, I saw a lot of water in the house. I said, "I better hurry up and save her." And when I swam in the house, my mother was in the corner. The pressure was against her. I swam over there and the pressure was against both of us. Suddenly I had an idea. I got two pans and I told my mother to sit on it and she did, and I gave her a broom and then I sat on my pan and got a broom. I told my mother to start rowing and she did. She started floating. I said, "It worked," and I started doing it and me and my mother were outside safe, and I got a reward for saving my mother and I.

I thought the dreamer had a special talent for saying clearly what her dream experience had been so it was possible for someone else to see 
something of it with her. This was quite an accomplishment for a child so young. Besides, the dream was engagingly dramatic. It tells the story of a dangerous adventure. There is a setting, characters, a plot, a crisis, a heroine, and climactic crisis resolution. There are emotions of fear, panic, courage, resoluteness, confidence, and approbation. There is ingenuity and a kind of rationale of transparent dream logic. We are delighted with her urgency and the resourcefulness with which she manages to respond to the challenge in her situation and to achieve recognition. Certain things we wish she had told us, for example, the cause and source of the flood, but she does not seem to concern herself with these questions. The dream begins abruptly, ends dramatically, and has a completeness to it. I could see how a nine-year-old girl could have had this dream. At nine years old one's parents are not as omnipotent as earlier. One begins to be skilled in managing some of life's challenges. I understood the dream to be about a child developing initiative. This seemed to me to be a plausible interpretation. The images were frozen for me in a psychologistic, individualistic, developmental framework, and from that point of view I understood it, and so I was essentially finished with the dream.

But the dream was not finished with me. It had a compelling, nagging urgency about it that caused me to look for other explanations. There were other theories I could apply to the dream, for example, the Jungian archetypes of the unconscious: water, house, mother, and the hero. The child consciousness was attempting to remain afloat in the waters of the unconscious. Another explanation was that the dreamer could be expressing a Freudian Electra complex: the wish to kill her mother was disguised into a story about saving her, or maybe the dream was about the classical Thalian concept of water as world substance, with the ever-present dialectic about whether things never change, or whether things are always changing. There was also American pragmatism in the dream: a creative search for what works. Maybe I should apply family systems theory: her mother might be an alcoholic who abused her; a witch, appropriately portrayed with a broom; or her mother could be a battered wife and this was a child burdened with having to rescue the family.

\section{The Dreamer}

These were some of the explanations I applied to the dream as I went back to the school to find the dreamer and ask her to talk to me about her dream. I found the children engaged in play. A few were indeed interested in talking about dreams, but I was summarily dismissed by my nine-year-old dreamer who had other more important games to play. I caught myself thinking in peeved frustration that she was not understanding the import of her dream. It seemed to me as if the dream was now more important to me than it was to her, or maybe she was too 
sensitive to talk about it. If there were any more questions about it, and there were, I had to find them encapsulated in the frozen symbols and in the many answers and theories I had so proficiently given myself. Yet things were becoming less clear. I was becoming progressively more engaged in the dream and at the same time less sure that I knew or had ever known its meaning.

During the next few days I attempted to position myself close to some of the children in order to increase the possibility that the young girl might talk to me. However, she never offered to tell me more about her dream and I did not directly ask. My role toward her was neither that of teacher nor that of therapist. I was a teacher-aide, one of the mothers who helped occasionally. I did not feel I could ask directly a question that a child had so deliberately avoided. It would have been invasive. My previous experience as parent to my own children had taught me that sometimes material from one's dream is either too difficult to articulate or too sensitive to tell. The dream puts into symbolic images what is familiar along with that which is just beyond familiarity. In a dream customary images carry within them meanings that are not customary and that are experienced as idiosyncracies, secrets, or mysteries. It is not surprising that children will tell only what they want to tell about their dreams. The fact that this child had been so articulate initially increased my frustrations and caused me to increase my reflections on my assumptions about the interpretation of her dream.

\section{The Interpreter}

The interpreter is part of the circle of understanding. This methodological point was not clear at first. Although I had not consciously taken myself out of the loop, it seemed erroneous to try to understand the dream without the dreamer's associations, interpretations, and intentions. Therefore, I was distanced further from the dream. I had assigned to the dreamer exclusively the expertise of experience and to myself exclusively the role of interpretation. I believed that if the dreamer could elaborate on the symbols, I could get at the correct interpretation by extracting meaning out of the (frozen) symbols. In light of the dreamer's absence it was difficult to accept the dream as a text independent of the dreamer, or to accept that my own experience was of any value in interpreting the dream.

However, it occurred to me that a dream is always a text written or spoken. The dreamer seems to be reporting something seen or experienced. Moreover, by the time the dream experience is told even to oneself it is a text, structural and culturally marked, and can speak both to the dreamer and to the hearer or reader. Examples of dream hearers participating in someone else's dream are most clearly demonstrated in what used to be described by Lincoln (1935) as culture 
pattern dreams and by Malinowski (1927) as official dreams. Moreover, among the Mae Enga of New Guinea and the Walbiri of Australia (Meggitt 1962; 1965), the dreams of youths in seclusion in the clan lodge were valued by all. In our own society, the phenomenon of the group dream has been described (Kaplan, 1973; Dombeck, 1988). We are reminded that although a dreamer has a unique perspective of a dream, he or she does not have privileged understanding or exclusive rights to it. However, in our society it is seldom the case that a dream of one individual is valued by others, least of all the dream of a child.

When interpreting a dream text, what the interpreter has in common with the dreamer becomes an important part of the interpretation. One of the most important things I had in common with this dreamer was the English language. This included a whole sphere of tacit linguistic assumptions about word-symbols in the dream. The way we understood certain word metaphors came from the fact that we shared a context (Lakoff \& Johnson, 1980). For example, I knew why someone living in an American urban environment in the late 20th century would want to use the word pressure. She had written "the pressure was against her." Why had she said it in that way? Had she just meant water pressure? Had she heard the word pressure from her mother? What were her understandings of pressure? I did not know. However, the word pressure was one that caused me to respond experientially and viscerally rather than just cognitively. I shared other important things with the dreamer, namely the memory of nine-year-oldness, little girlness, and daughterhood. The dream and I were now together under the same microscope. I was experiencing interpretation and I was being interpreted with the dream.

As I continued to ponder the dream, memories came to me of when I was nine years old. I was sitting in a classroom in Cairo, Egypt, the teacher was saying in a matter of fact way, "Egypt is the gift of the Nile." I knew exactly what that meant. If there had been no River Nile, there would be no Egypt, it would all be desert. I was also aware of a vague anxiety about the Nile flooding. It was not an acute anxiety, just a matter-of-fact understanding that the gift was occasionally too plentiful and could cause trouble to the gifted. The vague anxiety about flooding was something I shared with the adults, those who controlled my world. Thus I could conceive of a world where humans lived in the tension between either having not enough or too much water.

The text of the dream conveyed a matter-of-fact tone that nevertheless reminded me of a vague childhood anxiety about basic human survival. Could the child be experiencing survival issues directly? Or was she reflecting the anxiety of the adults around her? I could not stay with these questions because of my own frustration and anxiety. Yet as I reappropriated my memories, I became closer to the dream experi- 
entially. The child in the dream had successfully called to the child in me, and I was recalling not only the facts but also, and especially, the experience.

After a time of self reflection in relation to the dream I decided to study the mythology of water of ancient Egypt. This decision brought a new perspective to my relation with the dream. The dream became distant again. It seemed as if I could now see it with more objectivity as I headed for the libraries and the bookstores to find by reference to other stories, an expanded meaning of this one (Ricoeur, 1981, pp. 13-18).

However, the symbols in the mythology of Egypt did not shed any light or unlock any wisdom in the dream. The dream seemed to have a cosmic dimension to it that, somehow exceeded the flooding of a mere river. The dream also contained an element of ominous danger that found no resonance in the measured acceptance of death in the ancient Egyptians.

The dream seemed to be like the story of the Great Flood. I remembered learning about the story of the Flood in the Bible. But the symbols in the story of Noah and the Ark and the animals going in two-by-two had become too frozen and superficialized by familiarity to help either. Biblical commentaries and consultation with Biblical scholars led me to several other Near Eastern myths of creation and of the Great Flood. It was as I read these accounts that I became captivated by the Babylonian Myth of the Flood.

\section{The Myth}

What follows is a section from a Babylonian myth of the Flood. This particular version is from the Epic of Atrahasis. The tablet from which it was translated is dated in the reign of King Ammi-Sadugua of Babylon (1702-1682 BC).

\section{The Babylonian Myth of the Flood}

Atrahasis opened his mouth

And addressed his lord,

Teach me the meaning (of the dream)

... that I may seek its outcome.

(Enki) opened his mouth

And addressed his slave,

You say, "What am I to seek?"

Observe the message that I will speak to you:

Wall, listen to me!

Reed wall, observe all my words!

Destroy your house, build a boat

Spurn property and save life

The boat which you build. 
Roof it over like the Apsu

So that the sun shall not see inside it

Let it be roofed over above and below

The tackle should be tough, and so give

(the boat) strength.

I will rain down upon you here

An abundance of birds, a profusion of fishes

He opened the water-clock, and filled it,

He announced to him the coming of the flood

for the Seventh night.

... the flood (set out)

Its might came upon the peoples (like a battle array)

One person did not see another

They were not recognizable in the destruction

(The flood) bellowed like a bull

(Like) a whinnying wild ass the winds (howled)

The darkness (was dense), there was no sun

(Enki) was beside himself

(Seeing that) his sons were thrown down before him

Nintu, the great lady,

Her lips were covered with feverishness

Nintu was wailing

What? Have they given birth to the sea?

They have filled the river like dragonflies

Like a raft they have put in to the edge

Like a raft ... they have put in to the bank

For seven days and seven nights

Came the deluge, the storm, (the flood)

(Lambert \& Millard, 1969, pp. 89-97)

The passage tells of a great cataclysm. It is dark and noisy. The winds and waters are pictured as wild animals. Humans are drowning and floating in the water like dead flies. The Goddess is wailing with the wind. The God is beside himself. Having warned his protégé and filled his water-clock, he seems powerless against the deluge in which he himself participates. The human hero who has communicated with his God, presumably through a dream and also the wall of his reed hut, is now encased in a watertight boat that has been so carefully sealed that not even a ray of sunlight can penetrate it. This boat, however, is tough and strong and carries in it the hope of humanity to survive. It is curious that the God Enki has chosen to preserve mankind and that the Goddess Nintu is distraught about their demise. Who is Enki? What are the domains of his powerfulness and powerlessness? Similar questions about Nintu and about Atrahasis, the human who is chosen to be the only survivor and the parent of a new humanity. 
Some of the symbols of the myth were already dynamic and active for me when I found them. It was the dream of the nine-year-old girl that had sent me in search of them, so I was already a captive audience when the text spoke to me. The horizons of the two stories were blended, yet somehow distinct (Gadamer, 1975). To compare the dream of a nine-year-old girl with the myth of an ancient people was analogous to comparing an apple and whole orchard of oranges. What did a nine-year-old girl in upstate New York have in common with the ancient Babylonians and their complicated system of aqueducts and their equally complicated pantheon? But I was not comparing objectively. I was experiencing intersubjectively symbols from each story that were by now refusing to remain frozen and extending their boundaries into each other.

A living myth usually enlarges one's horizons. It does this by saying in story form what is difficult to express about what is most basic in human life. The symbols in a myth are fluid. Their meanings are hard to contain in fixed boundaries. That is why they are described as being multivocal, polysemic, and as having a surplus of meanings (Ricoeur, 1981). A myth is living when the hearer or reader of it is simultaneously drawn into recognizing something basic and familiar, and at the same time recognizing that the myth tells more than one had previously understood. This became true for me as I read the account of the flood. The flood is only a small part of the story. It is introduced in the context of creation, drought, and famine.

\section{The Myth in its Context}

The story begins at a time when things are different. There are seven great gods and numerous lesser ones. There are no humans. The gods have their domain in the ordered universe. Anu, the remote sky god to whom all defer, controls the heavens. Enki, Lord Earth, is down in the deep, sweet waters of the earth, the Apsu (Lambert \& Millard, 1969, I, p. 18). Enki also holds the great "bar of the sea" (Lambert \& Millard, 1969 , I, p. 15) in place, so that the chaotic sea in which are terrible sea monsters does not invade the earth. Nintu is the Great Lady of Earth. Enlil, the powerful Lord Storm the warrior god, controls the space between the heavens and the deep. In the beginning of the story the lesser gods are dissatisfied. They have been responsible for doing the work of the earth, have been overworked for 40 years, and are rebelling. They burn their tools, surround Enlil's temple, and declare war. Negotiations proceed between Enlil's spokesman and the rebels. But Enlil, with tears in his eyes, is inclined to solve the problem with a public execution.

This is not carried out. Instead, a decision is made to create Lullu (humans) to do the work and relieve the gods of their labor. The goddess of birth, called Nintu or Mami, is asked to create them. She 
accepts the task only if Enki provides the clay. They are both involved in the work of creation. Enki provides the clay and a purifying bath where a god full of life and "spirit" is slaughtered. Nintu thoroughly mixes the blood of the dead god, the clay, and the spittle of the living gods. This is only the first part of the creative task. Together they proceed to the "house of destiny" where he treads the clay and she recites incantations. Then she breaks off pieces of clay and makes men and women. Suddenly, this whole process becomes worked into the process for natural human childbirth. Nintu is now counting the months. There is a midwife, a mother who has just delivered, and a new baby. Everyone praises the goddess of birth, who is now called the Mistress of all the gods (I, p. 247). There are also instructions for confinement, sexual intercourse, marriage, and celebration (in that order).

The scene changes. People multiply and noise increases. The uproar sounds like a bellowing bull and disturbs Enlil, who decides to solve the problem by diminishing mankind. First he sends diseases. But Enki, who is partial to his creation, instructs his special protege Atrahasis to tell everyone to make the right sacrifices. The gods are placated and the plagues averted. Next Enlil withholds the rain and the earth becomes so parched that water does not rise from the deep. Enki again instructs Atrahasis about who to contact, and the earth is saved from drought. Humankind survives.

By now Enlil has lost so much sleep that he is furious. He causes the rains to be withheld again. The drought turns to famine. Fields are parched and white. People's faces are dry and cracked. Their bodies shrink, stoop, and look like dead people's bodies. Atrahasis begs Enki to intervene and Enki lets loose the "bar of the sea" just long enough to release enough fish to feed humankind. He restrains the water monsters while he does this so that humans are protected.

Enlil the executioner calls a meeting of the gods and enjoins them all never again to rescue mankind. But Enki becomes bored at the meeting and bursts into peals of laughter. Enlil takes this as a personal affront and persuades the other gods to bind Enki to an oath. Because Enki was responsible for creating and befriending humans and because he had used water for saving them, he will be bound by an oath to use water to destroy them completely. Enki is dismayed and tries to persuade the other gods to relieve him of this terrible task but they do not agree.

These are the events that lead up to the flood. Atrahasis is warned to build a boat. He obeys and becomes the hero, the savior of mankind and of other creatures. In spite of his importance as hero and survivor, he drops out of the story as abruptly as he was introduced. Humans are important, but not very. On the other hand, if we were to say that 
humans are the pawns of the gods, we would have to add that humans are important enough to be created, planned for, wept over, and saved.

After the flood, he presents an offering to the gods. Anu and Enlil are blamed for trying to destroy humankind. But they are placated and do not seem to be too disturbed that Atrahasis has escaped. They instruct Enki and Nintu to reorganize creation again. The story ends abruptly with a systematic ordering of society. The goddess is said to be wearing a necklace of lapis lazuli flies as a memorial of her dead children. In spite of the devastating destruction, the reader is left with a feeling of hope.

\section{Back to the Interpreter}

I read the story numerous times with great interest in the Babylonians who had ingeniously invented in the same story the terrifying images of, on the one hand, powerful gods with little compassion, and on the other hand, compassionate gods with less power. The story was not primarily about Atrahasis or about the flood. That was the vehicle for communicating the tragedy and glory of human contingency and human potential. The symbols made me pay attention to them, and to myself at multiple levels: I experienced myself with others as a speck of nothing floating dead in the water; I also experienced myself as part of the cosmos: a special new creation made of clay, spittle, and blood of the gods, saved for the purpose of carrying on the work of the universe.

As I read the translation of the expressions in the story containing water symbols like "the bar of the sea," "opening the water clock," the Lord of the Deep "giving birth to the sea," I began to become aware of the water symbols we use in our daily language: "still waters run deep," "dead in the water," "in over our heads," "muddy the water," "rock the boat."

I was now flooded and absorbed by a torrent of visual and linguistic images relentless in their intensity. They were images of water, life, pollution, death. The images were in my thoughts and words and in the natural world. I listened to rainstorms more carefully. I looked at water everywhere: clear water and muddy water, running water and stagnant water, drinking water and polluted water, fresh water and salty water. I had experienced all these things before, but now they were being reborn in me with a new sense of wonder.

I began to follow anxiously the accounts in the news about global warming and floods. Droughts and water pollution became a source of worry. Where is the water in the modern city? It seemed to me, as the experience continued, that in the city flowing, living water is no longer primarily in rain, streams, marshes, puddles, lakes, rivers, and seas. Water is mostly in faucets, hoses, gutters, fire hydrants, car washes, swimming pools, water closets, laundromats, showers, water tanks, 
and reservoirs. Water is also in cocktails, soda pop, and coffee. On wet days, rainwater mingles with the oil on the asphalt, making shining rivulets to the gutters, eventually flowing toward the river, and helping to flush the garbage into the sea. Occasionally, on hot summer days, a fire hydrant bursts and the cool waters wash some of the heat, dirt, and anger away. For others, there may be a dip in the cool, chlorinated waters of a swimming pool that washes some of the heat, dirt, and anger away, while they sip a stimulant, a depressant, or just a fizzy soda pop (Bachelard, 1942).

Where is the water in the modern city? I remembered the words of T.S. Eliot in The Waste Land (1958, p. 47):

Here is no water but only rock

Rock and no water and the sandy road

The road winding above among the mountains

Which are mountains of rock without water If there were water we should stop and drink

Amongst the rock one cannot stop or think

Sweat is dry and feet are in the sand

If there were only water amongst the rock

Dead mountain mouth of carious teeth that cannot spit

Here one can neither stand nor lie nor sit

There is not even silence in the mountains

But dry sterile thunder without rain

There is not even solitude in the mountains

But red sullen faces sneer and snarl

From doors of mudcracked houses

If there were water

And no rock

If there were rock

And also water

This modern poet recognized that life becomes a wasteland when there is too little that is life giving and authentic in our life. As I reread the ancient myth I recognized with terror what I had known for a long time: that we were kind of creatures who were made of mostly water who could die of thirst or by drowning. Beyond that, I became awed by a truth that was difficult to articulate. It came to me, not only like a biology lesson, but also like a memory of something deep within me. The lesson had something to do with life coming out of water. The ancient myth and the modern poem pointed back to the danger, the courage, and the victory in the dream.

\section{Back to the Dream}

The images in the dream were no longer frozen. Neither was I. I could embrace the symbols in the dream and the myth as if they were now symbols of myself. The dream and the myth did not mean the same 
thing exclusively, but they pointed to each other, including me in meanings that in their timelessness seemed crucially timely. Conversely, the dream, the myth, the nine-year-old girl, and I were each also more distinct and integral. For example, I could for the first time since reading the dream accept without frustration the possibility that little of what I had experienced in the recent months, had been relevant to the nine-year-old dreamer. For her the dream might have been experienced primarily as an expression of a developing autonomy or just a fun experience. However, my own engagement with the dream had disclosed the questions of ultimate survival and dauntless persistence posed by the dream, and hence possibly by the dreamer. Even if all the symbols frozen in her and in my cultural situation had made it possible for us to give interpretations and meanings that were clear, similar, and resonant, it was also true that making the symbols fluid interpreted something of who I was as a human woman of this time and place and who she might be as a girl of her time and place. The dream may have been dreamed by a nine-year-old girl in upstate New York, but it could also have been dreamed by me, or now that you read this, by you.

\section{Back to the Dreamer}

What of the child? She had drawn me into her dream by successfully portraying a story of great danger, courage, and hope in which she was protagonist and her mother a main character. After dismissing my initial assumptions about the meaning of her dream, she had at first seemed absent, yet had become increasingly present to me as I became more engaged with her dream. The dream had conveyed urgency because the source of nurture and the place of security were in danger (Bollnow, 1989). The girl correctly assessed the situation: the loss of the parent and safe place spell death, actual physical death or the symbolic death of one's childhood. The child's desperate desire to save her mother speaks of the primacy of nurturance not only for a child, but for all humans. "If she [mother] drowns, I'm going to kill myself." The absence of the parent alters the personhood and experience of the child. In the parent's absence the child becomes an orphan or a precocious pseudo-adult whose home is threatened.

Home is not merely a place, but an experience of unconditional acceptance where we can be who we are because of the presence, the memory, or the reflection of key persons in the space. The child had dreamed that her home was threatened and her mother in great danger. In the dream her mother was physically present but unable to protect her.

The myth put me in touch with how a child must feel in a world where some gods (adult godlike figures in a strange universe) are cruel and remote, while others (the familiar close ones) are compassionate and 
well-meaning but not always all-powerful. Children are usually aware of this paradox of powerfulness and powerlessness. In the dream, it was the child who was giving new life to both. The girl was giving birth to her mother.

\section{Back to the Interpreters}

Who is this mother we have to save? Who is the goddess who wails and creates? The little girl had written, "I better hurry up and save her" and "if she is dead, I am going to kill myself." It seems plausible that if our source of nurturance or creativity dies we could kill ourselves: we could actually kill our planet or symbolically kill our imagination and creative capacity to deal with our lives. The pressure is against all of us, but as in the dream, we could get an idea that will keep us afloat. New life can begin in our dreams, when dream symbols are thawed and allowed to flow back into dreamers, self-interpreters, and interpreters of humanity.

\section{Postscript}

The hermeneutic process stands by itself. It needs no explanation because it is in itself, if not an explanation or an interpretation, a process of understanding. However, it is important to point out that one embarks on the process as if it were all out there, in the text, and at the same time one looks for what is beyond the text. The hermeneutics of belief helps us to remain with the image long enough to surrender to it, and yet to resist the temptation of settling on a meaning too early. It says "yes" to the text. The "hermeneutics of suspicion" (Ricoeur, 1981, pp. 33-34) helps us to push the symbolic meaning beyond early obvious interpretations to what is not readily patent. The hermeneutics of suspicion is the instrument of multivocality, and at the same time a debunker of cultural illusion. The circle of understanding takes the interpreter on a journey between the two: namely, on the one hand, the surrender to the text that is an experience of closeness with the text, and, on the other, a critical exercise of looking at the text from a distance and from a perspective of other texts created in other cultural contexts.

How does one understand another? In Geertz' essay "From the Native's Point of View" he tells us that it is not necessary to be one to know one (Geertz, 1983, p 57). Yet when trying to understand the Natives it is almost impossible to come away without a better understanding of their personhood and their experience, as well as ours. So it is with dreams. A dream can be interpreted by oneself and/or by another, but it is the journey within the circle of understanding that expresses and deepens one's life.

In this experience the child told a dream about saving an adult's life and an adult was compelled to recognize it, if not as a "official dream" 
(Malinowski, 1927) certainly as an "important dream." In the beginning the interpreter saw the child as the "other" that could not be known; as the experience continued the interpreter became the "other." At the end of the experience the interpreter became a self by understanding another self. The child can grow to adult selfhood only when the adult can enter the child's world, and be present there, and the adult can understand mature selfhood only by being hospitable to the child's world. The entering of another's dream can make this possible.

\section{Notes}

1. The passage occurs as part of the prophecy of Isaiah (11:6):

The wolf shall dwell with the lamb and the leopard shall lie down with the kid, the calf and the lion shall browse together and a little child shall lead them.

Similar images occur in the old Sumerian paradise myth of Enki and Ninhursag

(Kramer, 1961).

Babylonian Patheon:

ANU High god-Sky god to who all defer.

Remote but crucial

Decrees but does not actively participate

ENLIL His jurisdiction is the Middle portion of the earth-the Executor.

Supervises the work of the Universe

Hard task master and ruthless slavedriver

LORD STORM-The Executioner

ENKI LORD EARTH-Lord of the deep

Lord of earth waters

Closest to Humans - understands humans

Argues with Enlil - Sense of humor

His presence is indwelling and intrinsic

NINTU MAMI-LADY OF BIRTH

The Mother Creator

Cooperates with Enki to create Lullu

Intercedes on behalf of humans

Wails, storms, criticizes and praises Anu

\section{References}

Bachelard, G. (1942). L'eau et les reves. Paris: Librarie Jose Corti.

Bollnow, O.F. (1989). The pedagogical atmosphere: The perspective of the child.

Phenomenology + Pedagogy, 7, 12-37.

Dombeck, M-T.B. (1988). Group mythology and group development in dream sharing groups. Psychiatric Journal of the University of Ottawa, 13(2) 97-106.

Eliot, T.S. (1958). The waste land. In The complete poems and plays. New York:

Harcourt Brace.

Gadamer, H.-G. (1975). Truth and method. New York: Seabury.

Geertz, C. (1983). Local knowledge: Further essays in interpretive anthropology. New

York: Basic Books.

Kaplan, S.R. (1973). The group dream. Interactional Journal of Group Psychotherapy $23,421-430$.

Kramer, S.N. (1961). Sumerian mythology. New York: Harper.

Lakoff, G., \& Johnson, M. (1980). Metaphors we live by. Chicago: University of Chicago

Press.

Lambert, W.G., \& Millard, A.R. (1969). Atra-Hasis: The Babylonian story of the flood.

Oxford: Clarendon Press.

Lincoln, J.S. (1935). The dream in primitive cultures. Baltimore: Williams and Wilkins. 
Malinowski, B. (1927). Sex and regression in savage societies. London: Routledge \& Kegan Paul.

Meggitt, M.J. (1962). Dream interpretations among the Mae Enga of New Guinea. Southwestern Journal of Anthropology, 18, 216-229.

Meggitt, M.J. (1965). Desert people. Chicago and London: University of Chicago Press. Ricoeur, P. (1981). Hermeneutics and the human sciences. Cambridge, MA: Cambridge University Press. 